\title{
Museu, objeto e informação
}

\author{
Museum, object and information
}

Durval de LARA FILHO'

\section{RESUMO}

Neste texto abordaremos a participação do museu na produção do conhecimento e a transformação do objeto em documento ao ser acolhido em seu interior. Ao assumir as consequências dessa transformação, o museu passa a trabalhar não só com bens materiais, mas simbólicos. O gestor de um acervo ou o curador de uma exposição não traz à luz o conteúdo que o documento encerra, mas fala por meio deles. Nesse sentido toda operação com documentos museológicos é de natureza retórica e ideológica - e portanto atribuída - desde a escolha do acervo até a exposição. O museu deve trabalhar com a busca do sentido, oferecendo a possibilidade de, a partir de correlações que se estabelecem na construção da informação, apresentar o objeto em seus diferentes contextos e sugerir possibilidades de apropriação e de participação efetiva dos públicos nas exposições.

Palavras-chave: museu; objeto; documento; documentação; apropriação.

\begin{abstract}
This text aims to approach museums' role in the production of knowledge and how objects are transformed into documents when museums incorporate them. On accepting the effects of such transformation, museums start working not only with material goods, but also symbolic goods. The collection manager or exhibition curator communicate through documents rather than bringing into light its intrinsic content. In this sense, every process involving museum documents, from the selection of collections to exhibitions, has a rhetoric and ideological nature which is given. Museums must search for meanings through correlations established in the process of producing information. Exhibitions should present objects in multiple contexts, giving visitors the opportunity to participate and attribute their own meanings to them.
\end{abstract}

Keywords: museum; object; document; documentation; appropriation.

\section{INTRODUÇÃO}

O que deverá ser o museu no século XXI? Quais modificações e acréscimos estas instituições existentes deverão discutir e propor para atualizar-se às demandas da contemporaneidade? E também, o que deverá ser um museu do século XXI - ou seja, uma instituição criada a partir das demandas da contemporaneidade? Estes dois eixos de discussão não se misturam e são até

1 Doutorando pelo Programa de Ciência da Informação da Escola de Comunicaçães e Artes, Universidade de São Paulo. Diretor da Divisão de Informação e Comunicação do Centro Cultural São Paulo. Rua Vergueiro, 1000, Paraíso, 01504-000, São Paulo, SP, Brasil. E-mail: <durval@usp.br>.

Recebido e aceito para publicação em 21/8/2009. 
conflitantes. Enquanto o processo de atualização (em seu papel e funções e não em seus acervos) vem ocorrendo ao longo do tempo. A criação de um novo tipo de museu em nossos dias é até mesmo contestada, vista por alguns como contraditória em seus termos ("novo" e "museu") (Lara Filho, 2007).

museu é local de contemplação, de fruição, de prazer; possui compromissos educacionais, funções sociais, mas principalmente insere-se no universo do conhecimento. Nele, o objeto surge como documento, como um "suporte de significações" (Bezerra de Meneses, 1994, p. 24) e a exposição como um discurso ou narrativa que visa a produção de sentido. Para Ulpiano Bezerra de Meneses (1994, p.14), "rigorosamente todos os museus são históricos", pois operam nas dimensões de espaço e tempo, como nas palavras de Crang, " as machines that incribe time in space" (1994) apud Bezerra de Meneses (1994) "as machines that inscribe time in space", quer seja como organização sincrônica ou diacrônica. A taxonomia dos museus "tende à reificação" ou à "fetichização" ao basear-se mais nos tipos ou categorias de objetos de seu acervo do que em "campos de conhecimento e problemas humanos".

No entanto, mesmo sendo uma instituição pública e aberta, muitas vezes de acesso gratuito, a frequência aos museus é muito baixa se comparada a outras atividades culturais. Dados do Ministério da Cultura (MinC) mostram que o Brasil conta com 2.618 museus (sendo 442 apenas no estado de São Paulo). Dos mais de cinco mil municípios apenas 18,01\% possuem um ou mais museus, percentual que sobe para mais de 94\% no caso das bibliotecas (Brasil, 2009). Em relação à frequência, pelos dados da última pesquisa do Instituto Brasileiro de Geografia e Estatística (IBGE) e do Instituto de Pesquisa Econômica Aplicada (IPEA), 92\% da população brasileira nunca visitou um museu e 93\% nunca foram a uma exposição de arte (Setor..., 2008). São números que revelam a enorme distância entre o museu e as pessoas. Como instituições públicas que são, os museus devem preocupar-se e empenhar-se na busca de caminhos que possam diminuir esta distância e aumentar a presença do público em suas dependências. Não se trata de traçar uma estratégia de marketing mas de repensar sua inserção na cultura contemporânea.

Desvallées refere-se à necessidade do museu buscar "outro conteúdo" se pretende chegar ao chamado "não-público", isto é, aqueles que não têm o hábito de freqüentá-lo (Desvallées, 2001, p.3). Os desdobramentos destes debates apontaram os caminhos da chamada Nova Museologia reafirmando o princípio de que a coleção não pertence a uma determinada instituição, mas a toda a humanidade, e também para um novo papel que o museu deveria ter ao utilizar o patrimônio como "suporte do conhecimento" para fazer dessa instituição "um lugar de reflexão crítica para todos, proporcionando-lhes conhecimentos que não podem ser adquiridos no exterior - nem no cinema, nem na televisão. Nem sequer na escola!" (Desvallées, 2001 , p.4).

Neste texto não iremos nos deter nos aspectos da documentação museográfica e organizacional dos acervos e seus instrumentos de controle administrativo, gestão, estudo científico e conservação de objetos e obras. Aqui abordaremos especialmente a participação do museu na produção do conhecimento e a transformação do objeto em documento ao ser acolhido em seu interior. Assim, nosso enfoque dirige-se à formação dos acervos, às exposições e os processos de apropriação pelos públicos que as visitam.

\section{ANTECEDENTES DO MUSEU MODERNO}

Museu tem uma história recente. Ele passa a ser formalmente considerado como uma instituição pública somente na segunda metade do século XVIII, período das revoluções democráticas. Suas funções tradicionais - a aquisição, a preservação e a exibição de objetos -, que estão presentes ainda hoje, foram formuladas a partir de uma visão do museu como um local de afirmação da nacionalidade onde se guardavam os vestígios eleitos de seu passado, representados por tesouros e relíquias. Muitos dos museus de Belas Artes e Históricos mais se pareciam com almoxarifados que entesouravam as pilhagens feitas pelos países colonialistas dos séculos XVIII e XIX, no Egito, Grécia, Oriente e África.

No entanto o pensamento sobre o museu sempre manteve estreitos vínculos com a escola e com o conhecimento. De acordo com Mairesse (2004), em 1565 Samuel Quiccheberg ${ }^{2}$ publica um pequeno

\footnotetext{
2 Samuel Quiccheberg (1529 - 1567) nasceu nos Países Baixos e morreu aos 38 anos em Munique, Alemanha. Foi conselheiro cultural do Duque lbert V da Baviera, "particularmente encarregado das aquisições e classificação de suas coleções"
} 
volume (Inscriptiones vel tituli theatri amplissimi, 1565) no qual prescreve alguns parâmetros para se organizar uma exposição de acordo com um projeto enciclopédico, em que fica clara uma intenção "pedagógica" desses conjuntos nos quais as imagens e os objetos são os meios para se chegar ao conhecimento universal. Sua proposta não pretende apenas isso, mas também o deslumbramento e a discussão. Mairesse vê, em Quiccheberg, o início da passagem do Musaem da antiguidade para o museu moderno, que irá voltar-se, cada vez mais, para próprio objeto como portador de informação e não mais como suporte da memória.

É somente a partir do século XIX que as ideias de Quiccheberg adentram os museus que passam a se preocupar com a conservação dos documentos escritos, o registro das informações, as classificações, a organização das bibliotecas, os catálogos, os inventários. "E é nesse tempo classificado, nesse devir quadriculado e espacializado que os historiadores do século XIX tentarão escrever uma história enfim 'verdadeira' - isto é, liberta da racionalidade clássica, da sua ordenação e da sua teodiceia, uma história restituída à violência irruptiva do tempo" (Foucault, 1996, p. 177).

A nova ordem estabelece um distanciamento das palavras e das coisas, a partir do qual os objetos não mais escondem uma verdade a ser desvendada. A observação, o documento e a fábula separam-se e a linguagem desprende-se do objeto que já não mais fala por si mesmo, mas através da intermediação da linguagem que se torna uma forma de organização das coisas. Para Foucault (1996), nesses espaços a classificação se faz pelo visível, pela anatomia e nomear equivale a conhecer. Os objetos são agrupados a partir de uma ordem, de identidades e graus de diferenciação, e não mais pela semelhança, parentesco, atração ou uma natureza secretamente partilhada. É o momento de "discernir, estabelecer as identidades, e a seguir todos os graus de diferenciação". O texto já não mais faz parte dos signos e das "formas da verdade" e a linguagem deixa de ser uma "coisa da natureza" cujas marcas estão impressas nas coisas desde o princípio dos tempos. A verdade manifesta-se pela percepção e as palavras devem traduzi-la.

Em finais do século XIX e princípios do século XX o museu passa por transformações significativas, acompanhando a ebulição cultural de seu tempo. É nesse período que surgem importantes contribuições - muitas delas vindas de fora da área da museologia tradicional - e que vão configurar novas abordagens sobre os acervos, as exposições e os processos de apropriação de seu significado e conteúdo pelo público. Uma dessas importantes contribuições foi dada por Paul Otlet (1934) ao introduzir o conceito de documentação e aplicá-lo aos objetos do museu.

\section{PAUL OTLET, O CONCEITO DE DOCUMENTAÇÃO E O MUSEU}

Para Paul Otlet (1934), o criador do termo documentação, ao colecionar objetos e documentos o museu aproxima-se da biblioteca e do arquivo, no plano funcional, uma vez que todos eles trabalham com coleções, catálogos, classificações, identificação, conservação etc. Otlet não vê a mostra ou exposição como uma operação documentária, salvo em casos particulares, mas defende os princípios de organização e tratamento dos objetos como documentos visando extrair deles uma quantidade de informações com o objetivo de mostrar de forma didática, inteligível e agradável. É talvez por isso que vê as Exposições Universais, embora efêmeras, como um importante marco a ser apreciado e seguido. Otlet vê no museu moderno uma "forma e um método", portanto uma solução aplicável a diversos domínios.

museu é visto, por Otlet, como um centro de documentação que tem grandes semelhanças, no plano funcional, com a biblioteca, pois ambos trabalham com coleções, catálogos, classificações, identificação, conservação etc. Analisando os museus de sua época vê um período de grandes mudanças: os museus, que antes eram locais apenas para se conservar objetos raros e preciosos, agora, sem prejuízo deste caráter, devem transformar-se em centros de documentação para objetos ("documentos em três dimensões"); deve mostrar as relações e encadeamentos entre os objetos da coleção lançando, se necessário, textos e comentários sobre eles.

Para este autor o 'trabalho museográfico' demanda a escolha e reunião de obras e objetos, sua identificação e classificação, a preparação de um catálogo sobre elas, a disposição das obras e objetos para a apreciação do público e o estabelecimento de intercâmbio com outras instituições. Otlet defende que 
as coleções do museu não devem ser criadas de qualquer forma, mas seguindo um método e uma sistematização na escolha das peças que irão compor os acervos. A classificação das obras e objetos pode ser feita seguindo diversos critérios - cronológicos; geográficos ou outros -, dependendo das características e propósitos do museu e da natureza do acervo. Num museu documentário, diz ele, o visitante encontrará os objetos "ordenados sistematicamente numa representação evocadora da vida" (Otlet, 1934, p.358). O catálogo deve ser um guia para o visitante e deve ser composto por uma introdução sobre o museu e a coleção, além de informações sobre os objetos expostos acompanhando sua disposição em cada sala. A exposição dos objetos e obras deve seguir uma técnica de modo a valorizá-los, lançando mão de artifícios que facilitem a compreensão dos visitantes, como máquinas que mostram seu funcionamento interno ou que funcionem mediante o acionamento de um botão, cenários em miniatura com os objetos apresentados de "forma dramática", filmes e projeções complementares aos objetos expostos.

Otlet discorre ainda sobre os espaços expositivos que, para ele, têm de ter uma arquitetura funcional. Um museu deve ser um "tratado visualizado, objetivo e sinóptico" (Otlet, 1934, p.358), cujas divisões devem seguir os mesmos princípios daqueles dos livros capítulos, seções e parágrafos que desembocam nas frases e palavras. Os espaços expositivos devem ser grandes, retangulares, bem iluminados e divididos por divisórias móveis que formarão as salas

O Atlas Universalis Mundaneum, proposto por Otlet, é uma síntese de informações apresentadas com o uso de recursos visuais. Esses grandes quadros sintéticos sobre os mais variados assuntos, eram especialmente recomendados para exposições e mostras. Eles deveriam ser pensados como unidades de um conjunto maior, o que permitiria a combinação mais adequada a cada situação, a comparação entre eles, a cronologia de fatos e outras formas de apresentação.

No entanto, ao valorizar a ordem e estabelecer um forte compromisso com a origem, a história, a conservação, a organização do acervo e a autenticidade das obras, muitos museus tornam-se instituições mais próximas dos especialistas do que do público, contrariando os princípios iluministas da emancipação pelo conhecimento e pela universalização. A catalogação, a classificação e a organização da coleção com finalidades educacionais ocupam lugar de destaque e, em alguns casos, exagerado. Um exemplo é a famosa citação George Brown Goode ${ }^{3}$ que definia uma experiência educacional eficiente num museu como sendo aquela em que há uma coleção de etiquetas instrutivas acompanhadas de espécimes bem escolhidos (Vergo, 1993).

\section{OBJETO E MEMÓRIA; OBJETO E FETICHE; OBJETO E DOCUMENTO}

Qualquer atividade relativa à organização dos objetos do museu traz, subjacente, um princípio de interpretação e uma ideia de divulgação. A separação entre a posse do objeto e o acesso ao conteúdo (quem detém o objeto não mais monopoliza o conteúdo) acontece desde a passagem da coleção privada para o museu e amplia-se muito com os dispositivos de comunicação de massa. As novas tecnologias e a reprodutibilidade técnica parecem favorecer uma espécie de "poder distribuído" e, assim, deslocam a interpretação a partir de uma camisa-de-força imposta, de um inculcamento, para a esfera da apropriação.

Para Bezerra de Meneses (1994, p.31):

\begin{abstract}
o museu é essencialmente uma forma institucionalizada de transformar objetos em documentos" e "o processo de transformação do objeto em documento (que é, afinal, o eixo da musealização), introduz referências a outros espaços, tempos e significados numa contemporaneidade que é a do museu, da exposição e de seu usuário.
\end{abstract}

Qualquer objeto musealizado tem uma função documental. Mas esta característica não pode e nem deve ser confundida com a informação latente do objeto, aquela que ele encerra por suas características físicas. O historiador ou o curador de uma exposição "não faz o documento falar" é o historiador ou curador quem fala e "a explicação de seus critérios e procedimentos é

\footnotetext{
3 George Brown Goode (1851-1896), cientista, administrador de museu e historiador da ciência. Foi secretário assistente do Smithsonian Institution e responsável pelo seu Museu Nacional. Suas obras tiveram grande influência sobre os museus históricos de todo o mundo (Smithsonan..., c2009.)
} 
fundamental para definir o alcance de sua fala. Toda operação com documentos, portanto, é de natureza retórica" (Bezerra de Meneses, 1994, p.21) e ideológica - e portanto atribuída - desde a escolha do acervo até a exposição.

Essa atribuição de sentido presente numa exposição por meio da narrativa curatorial se mostra na escolha dos objetos, em seus agrupamentos, relações e formas de apresentação. No entanto a visão tradicional do Museu coloca a coleção e o público como entidades separadas e distantes, cada qual com suas especificidades. Nesta relação trabalha com o pressuposto de que a narrativa curatorial conta e explica situações e cabe ao público decifrá-las. Para romper este fosso existente entre a narrativa e o público, recorre-se principalmente a "ações educativas" que procuram criar "pontes" entre ambos. No entanto, é preciso cautela pois o museu quando visto como uma instituição paralela ou similar à escola leva a um paradoxo: "em vez de facilitar o acesso à obra de arte, o destaque dado à ação educacional reforça a idéia, no público leigo, de que de fato as portas da arte só se abrem depois do esforço representado por um treinamento orientado" (Coelho, 1997, p.275). O problema não se resolve na falsa dicotomia entre "aproximar" o público de um saber hegemônico constituído pela cultura erudita por meio de ações educativas e nem de "aproximar" a arte do público leigo, transformando o museu num grande parque de diversões. Falamos em falsa dicotomia porque ambas trabalham na mesma matriz que é o processo de "enculturação", conforme Coelho (1997, p. 165), no qual os esforços são dirigidos e ordenados para um fim prédefinido.

Outro aspecto a destacar é o processo de descontextualização do objeto ao ser retirado de seu local de origem e transportado para as salas de exposição, gerando novas camadas de sentido. Para Deloche (2002), tudo aquilo que é exposto no museu torna-se simultaneamente "objeto e produto de sua substituição", já que ocorre um processo de "desfuncionalização". Mostrar ou expor é transformar um objeto em imagem ${ }^{4}$, e é assim que o museu desenvolve um jogo de "descontextualização e recontextualização". Ao deslocar um objeto ou documento de seu contexto e colocá-lo em outro, o museu passa a abrigar fragmentos e com eles articula suas narrativas.

Trata-se de verificar se é possível e desejável recontextualizar aquilo que foi descontextualizado. Em outras palavras, de constatar se seria viável e desejável recuperar os contextos de um objeto musealizado e reintroduzí-lo na exposição, porém, sem perder as novas relações estabelecidas no museu. Seria preciso localizar tais contextos e conceituá-los de forma conveniente. Certamente não estamos aqui falando das reconstituições cenográficas de ambientes, que congelam arbitrariamente um dos contextos. Embora não se negue seu valor, as cenografias não conseguem representar ou trazer de volta a complexidade dos diversos contextos. Por isso

[...] o sentido "verdadeiro" da Mona Lisa não é o de seu contexto original de produção, nem o de qualquer outro contexto individualizado (fruição, musealização), mas as diversas superposições de sentido que referenciam sua trajetória histórica, do Renascimento até sua projeção no mundo da publicidade e da indústria cultural. (Bezerra de Meneses, 1994, p.31).

Este enfoque abandona as propostas de recuperar um "sentido original" e da criação de narrativa fechadas com intenções de "explicar", "ensinar", "adestrar" ou ainda "transferir" para o público algo pronto, dirigido e ordenado para um fim pré-definido. Ao contrário, a mobilização de diversos contextos formariam camadas de sentido superpostas ao longo da história do objeto de modo a permitir diferentes leituras e associações a partir de diferentes repertórios.

González de Gomes (2004, p.66) utiliza o conceito de museu como um dispositivo informacional que abriga objetos fronteiriços:
Se pensarmos em um objeto musealizado como objeto fronteiriço, poderíamos considerar que [ele] estabelece elos entre os produtores origi- nários do objeto e do mundo de sua produção (uma cerâmica utilitária indígena), os museólogos e curadores que o incluem em uma exposição sobre cultura marajoara do Pará (um

4 termo imagem é polissêmico. Para Deloche (2002) a imagem é uma representação ou reprodução mental de uma percepção ou sensação anterior depois reintroduzida no real "experimentado," uma parcela do mundo real que isolamos. Utilizamos a expressão imagem visual para a imagem funcional reproduzida por meios técnicos. 
objeto de valor antropológico, estético ou histórico), e o público do museu que pode olhá-lo das mais diversas maneiras, considerando seu valor decorativo ou vendo nele uma lembrança das férias artesanais de sua terra natal. $\bigcirc \mathrm{mu}$ seu seria assim um dispositivo informacional que pode reconstruir as malhas que ligam seus objetos museais aos diversos universos culturais de origem e destinação.

Nesta ótica, o objeto considerado como documento "introduz referências a outros espaços, tempos e significados" (Bezerra de Meneses, 1994, p.32), criando-se assim uma rede dinâmica na qual os acervos, as exposições e as diferentes apropriações estabelecem jogos de posições móveis. Susan Pearce (1992) apud Bezerra de Meneses (1994) lança mão da terminologia saussureana para exemplificar a busca de sentido que se vê no museu. Para ela um conjunto de evidências materiais de uma cultura é um repertório (langue) de onde seleciona-se um grupo de objetos que irá formar uma coleção ou acervo ("atualização do potencial da langue, portanto parole"). Esta coleção funciona como um repertório (langue) "que será acionado como parole na exposição". A exposição, por sua vez, é um repertório (langue) que pode se tornar parole com a apropriação numa dinâmica recursiva que caracteriza o aprendizado. Cada degrau desta construção é simultaneamente langue e parole, dependendo da referência que toma. A parole é construída a partir de regras e escolhas.

\section{MUSEU E APROPRIAÇÃO PÚBLICA DA INFORMAÇÃO}

As observações anteriores permitem estabelecer relações com as reflexões contemporâneas do campo da Ciência da Informação (Cl) que também enfatizam as interrelações entre conhecimentos (e contextos) e entre eles e os usuários.

Conforme afirma Hjorland (2003) apud Capurro (2003), o objeto da Ciência da Informação, hoje, é o "estudo das relações entre os discursos, áreas de conhecimento e documentos em relação às possíveis perspectivas ou pontos de acesso de distintas comunidades de usuários", que desenvolvem seus critérios de acesso ou relevância.
Semelhante afirmação põe em destaque o fato de que a transformação do objeto do museu em documento de modo a inseri-lo no conjunto dos processos de conhecimento não tem um fim em si mesmo. Pelo contrário, procura responder às novas perspectivas do museu no sentido de, como instituição, observar as demandas ou mesmo propor-se a criá-las, respondendo, assim, ao seu novo papel que combina a fruição às funções sociais de desencadear processos de significação e de conhecimento. Ao assumir as consequências da transformação do objeto em documento, o museu trabalha não só com bens materiais, mas simbólicos.

De fato, como afirmam Kobashi e Tálamo (2003, p. 19) "nenhum bem pode ser analisado ao largo do sistema que o institui como tal". Pela sua natureza bem material e simbólico - a informação desencadeia fluxos (de produção, disseminação, acesso, troca, uso). $\mathrm{Na}$ produção estabelece relações entre conteúdo e forma de apresentação; na disseminação, entre os produtos que oferece e os diferentes tipos de usuários; no acesso, entre a linguagem do sistema e a do usuário; na troca, entre o capital cultural de seus públicos e o modo de veiculação simbólica do acervo; no uso, entre a informação disponibilizada socialmente e a possibilidade de subjetivação. A informação se mostra, assim, como um objeto que tem uma face social e outra subjetiva que se complementam.

Nessa perspectiva, "a diferença entre mensagem ou oferta de sentido e informação ou seleção de sentido" é crucial para a $\mathrm{Cl}$, entendida como teoria das mensagens e não como teoria da informação. Esta proposta segue Luhmann (1987) apud Capurro (2003) que concebe a comunicação como uma unidade desses três momentos: oferta de sentido, seleção e compreensão. Ou dito de outro modo, o museu, nos dias atuais, deve trabalhar com a busca do sentido, oferecendo a possibilidade de, a partir de correlações que estabelece na construção da informação, apresentar - objeto em seus diferentes contextos e sugerir possibilidades de apropriação e de participação efetiva das exposições.

A proposta acima pressupõe uma política de caráter hermenêutico na qual a relevância para o usuário inclui a possibilidade de negociação que, conforme Froelich (1994) apud Capurro (2003), deve combinar: uma hermenêutica dos usuários, capazes de interpretar suas necessidades em relação a si 
próprios, a intermediários e ao sistema; uma hermenêutica da coleção que seja capaz de fundamentar os processos de seleção de documentos ou textos e a forma como esses são indexados e catalogados; - uma hermenêutica do sistema intermediário, na qual tem lugar o clássico matching a que se refere o paradigma físico.

Na Ciência da Informação, essa perspectiva encontra-se inserida no paradigma social que funda o conhecimento teórico num pré-conhecimento prático tácito: a recuperação da informação - acrescentaríamos, para os museus: como também a atribuição de sentido na fruição - funciona como um tipo de conversação sustentada por um andaime e o estudo de campos cognitivos está em relação direta com comunidades discursivas (...). No caso dos museus, ao invés de promover a reificação dos objetos baseando-se em categorias de objetos, os museus têm de observar que operam nas dimensões do tempo e do espaço, com campos do conhecimento, com o simbólico, com os problemas humanos e, enfim, com a articulação entre todos esses elementos.

\section{REFERÊNCIAS}

BEZERRA DE MENESES, U.T. Do teatro da memória ao laboratório da história: a exposição museológica e o conhecimento histórico. Anais do Museu Paulista, v.2, p. 9-41,1994.

BRASIL. Ministério da Cultura. Noticias do MinC: o dia-a-dia da Cultura. Brasília, 2009. Disponível em: <http:// www.cultura.gov.br/site/2009/02/05/cadastro-nacional-de-museus-revela-novos-numeros-brasil-tem-mais-de-26-milinstituicoes-museologicas/>. Acesso em: 21 jul. 2009.

CAPURRO, R. Epistemologia e Ciência da Informação. In: Encontro Nacional de Pesquisa em Ciência da Informação, $5 .$, 2003, Belo Horizonte. Anais... Belo Horizonte: ENANCIB, 2003. Disponível em: <http://www.capurro.de/enancib_p.htm>. Acesso em: 21 jun. 2009

COELHO, T. Dicionário crítico de política cultural. São Paulo, Editora lluminuras, 1997.

DELOCHE, B. El museo virtual. Gijón. Astúrias: Ediciones Trea, 2002. (Colección Biblioteconomía y Administración Cultural, 81).

DESVALLÉES, A. Que futuro para os museus e para o patrimônio cultural na aurora do terceiro milênio: conferência proferida durante o encontro do APOM, Casa da Eletricidade, Funchal. Revista da APOM, n. 1, p.46-74, 2003. Disponível em: <http:// www.dhis.uevora.pt/cursos/mest_pos/mp_mus_doc/ hismus tl tmr.pdf>. Acesso em: 25 mar. 2005.

FOUCAULT, M. As palavras e as coisas. São Paulo: Ed. Martins Fontes, 1966.

GONZÁLEZ DE GOMEZ, M.N. Novas fronteiras tecnológicas das ações de informação: questões e abordagens, Ciência da Informação,.v.33, n. 1, p.55-67, 2004.
KOBASHI, N.Y.; TÁLAMO, M.F.G. Informação: fenômeno e objeto de estudo da sociedade contemporânea. Transinformação, v. 15, n.3, p.7-21, 2003.

LARA FILHO, D. O museu no século XXI ou o museu do século XXI? Revista do Fórum Permanente: espaço aberto ao pensamento coletivo. 2005. Disponível em: <http://www.forumpermanente. org/.painel/artigos/dlf_museu/?searchterm=durval\%20lara $>$. Acesso em: 21 jul. 2009.

MAIRESSE, F. Samuel Quiccheberg et le patrimoine immaterial. In: International Symposium: museology and intangible heritage 2, Seoul, Korea: ICOFOM, Oct. 02-08, 2004. Complete edition of the papers, München: ICOFOM: 2004, p.54-61. Disponível em: <http://www.Irz-muenchen.de/ iims/icofom/ iss33_supplement.pdf>. Acesso em: 21 jul. 2009.

OTLET, P. Traité de documentation: le livre sur le livre, théorie et pratique. Bruxelles: Editiones Mundaneum; Palais Mondial, 1934.

SETOR privado contribui na reformulação da Lei Rouanet. Cultura e Mercado, 11 dez., 2008. Disponível em: <http:// www.culturaemercado.com.br/post/setor-privado-contribui-nareformulacao-da-lei-rouanet/>. Acesso em: 24 jul. 2009.

SMITHSONIAN Institution National Museum of Natural History. c2009 Disponível em: <http://www.mnh.si.edu/vert/fishes/baird/ goode.html>. Acesso em: maio 2006.

VERGO, P. The reticent object. In: VERGO, P. (ed.). The new museology. London: Reaktion Books, 1993. cap.3, p.41-59. 
